\title{
PENDEKATAN TERITORI PADA FLEKSIBILITAS RUANG DALAM TRADISI SINOMAN DAN BIYADA DI DUSUN KARANG AMPEL MALANG
}

\author{
Rr. Putri ${ }^{1}$, PANGARSA, Galih Widjil' ${ }^{2}$, dan ERNAWATI, Jenny ${ }^{3}$ \\ ${ }^{1}$ Mahasiswa S2 Arsitektur Lingkungan Binaan Universitas Brawijaya, Malang \\ 2,3 Jurusan Arsitektur Universitas Brawijaya, Malang \\ Email: jny23ern@yahoo.com,mappapoo3@yahoo.co.id, galihwpangarsa@gmail.com
}

\begin{abstract}
ABSTRAK
Penelitian ini bertujuan untuk mengidentifikasi dan menganalisis pendekatan teritori pada fleksibilitas ruang dalam tradisi sinoman dan biyada di Dusun Karang Ampel Malang. Metode yang digunakan dalam penelitian ini adalah deskriptif kualitatif dengan menganalisis hasil identifikasi pembentukan teritori berdasar perubahan karakteristik dan fungsi publikprivat ruang. Pengambilan sampel dilakukan secara purposive sampling dengan kriteria kedekatan hubungan kekerabatan dan perbedaan ketersediaan ruang terbuka pada objek amatan. Hasil penelitian menunjukkan bahwa hubungan kedekatan kekerabatan tidak berpengaruh terhadap pembentukan perluasan teritori, akan tetapi perbedaan pola pembentukan teritori lebih karena dipengaruhi faktor ketersediaan ruang terbuka (pelataran belakang).
\end{abstract}

Kata kunci: Teritori, fleksibilitas ruang, sinoman dan biyada.

\begin{abstract}
The research aim is to identify and analize territorial approach of space flexibility in sinoman and biyada tradition in Karang Ampel Village Malang. The method used in this research is descriptive qualitative method by analyzing the results based on the results of the identification of characteristic and public-private function space changes. Sampling was done by purposive sampling criteria kinship closeness and differences availability of open space on observed objects. The results showed that the closeness of kinship ties have no effect on the formation of territorial expansion, but the differences in patterns of territory establishment as influenced by the availability of more open space (the back yard)
\end{abstract}

Keywords: Territory, flexibility of space, sinoman and biyada.

\section{PENDAHULUAN}

Eksistensi gotong royong yang pada saat ini semakin jarang dijumpai, ternyata masih dapat dijumpai di dusun Karang Ampel, Kecamatan Dau, Kabupaten Malang. Dusun Karang Ampel terletak di sebelah barat laut kota Malang dan merupakan wilayah kabupaten yang berbatasan dengan kota Malang. Dusun Karang Ampel merupakan daerah yang terletak di area perbukitan dengan kondisi tanahnya yang subur dengan kontur yang cukup datar di area pemukiman. Sebagian besar warga bermata pencaharian sebagai tukang dan berkebun.

Kebersamaan dalam bermasyarakat yang dimiliki oleh warga dusun Karang Ampel yang terwujud dalam gotong royong yang telah mentradisi ini dipahami masyarakat sebagai salah satu pemenuhan kebutuhan sosial dalam berkehidupan, sebagaimana dalam Ronald (2005) menyebutkan bahwa masyarakat Jawa meyakini bahwa dalam kehidupannya, mereka membutuhkan berasosiasi dengan lingkungannya, baik dengan sesama manusia, hewan, dan lingkungan sekitarnya. Kebutuhan berasosiasi tersebut dalam rangka untuk memenuhi kebutuhan lahir dan batin dalam bermasyarakat.

Semangat kebersamaan dalam gotong royong di beberapa aspek kehidupan di desa Karang Ampel ini terwujud dalam beragam kegiatan, termasuk di dalamnya tradisi sinoman dan biyada. "Sinoman", dari kata "sinom" yg sebenarnya adalah nama daun pohon asam. Kemiripan "sinom" dengan kata "anom" yg berarti muda menjadikan sinom sebagai istilah sebutan bagi kaum muda atau "kadang wiranem". "Nyinom", istilah untuk melakukan pekerjaan sinom dilakukan umumnya oleh pemuda-pemudi di suatu perkampungan. Biasanya keluarga yg mempunyai hajat alias ewuh meminta tolong pada para pemuda untuk menjadi "pramuladi". Pramuladi merupakan istilah lain sinoman yg sama-sama bermakna pelayan tamu. Begitu perhatiannya orang Jawa dalam menyambut dan melayani tamu, sampai-sampai segalanya dipersiapkan secara detail. (Assulaiman, 2009). Sinoman dan biyada dipahami masyrakat desa 
Karang Ampel sebagai salah satu bentuk gotong royong dalam hal membantu tetangga yang sedang menyelenggarakan hajat, yaitu hajat pernikahan dan khitanan. Sinoman dilakukan oleh para pria, sedangkan biyada dilakukan oleh wanita. Pada umumnya sinoman dan biyada dimulai sejak 3 hari sebelum hari pelaksanaan (H-3) sampai dengan hari pelaksanaan (hari $\mathrm{H}$ ).

Tradisi sinoman dan biyada ini juga dilakukan di beberapa desa tetangga lainnya. Namun, yang menarik di desa Karang Ampel ini lokasi desa ini yang terletak di sebelah barat dan berbatasan dengan kota Malang dan sebagian besar warganya bermatapencaharian di kota Malang, sehingga arus informasi dari luar desa masuk ke dalam desa sangat cepat, sehingga secara fisik perubahannya sangat cepat mengikuti perubahan trend, akan tetapi secara sosial, mereka berhasil mempertahankan tradisi yang diturunkan dari nenek moyang mereka. Jika dibandingkan dengan desa-desa lain dari utara, selatan, dan timur kota Malang, yaitu daerah desa Wagir (desa di yang berbatasan dengan wilayah kota Malang bagian selatan), daerah desa Wendit (desa di yang berbatasan dengan wilayah kota Malang bagian timur), dan daerah desa Karangploso (desa di yang berbatasan dengan wilayah kota Malang bagian utara) tradisi sinoman dan biyada di desa Karang Ampel lebih kental nuansa kebersamaannya, hal ini dapat dilihat dari kebersediaan warga untuk meluangkan waktu yang lebih panjang untuk mengikuti tradisi sinoman dan biyada, yang rela meliburkan diri dari pekerjaannya selama 4 hari untuk nyinoman ataupun mbiyada. Pelaksanaan sinoman dan biyada di desa-desa tersebut hanya terjadi pada saat acara, yaitu pada saat nduwe gawe, dan itupun sebagian besar merupakan keluarga yang didatangkan dari berbagai daerah, tidak banyak tetangga sekitar yang ikut terlibat di dalamnya, sehingga secara ruang pun pemanfaatan ruang-ruang bersama pada umumnya terjadi hanya pada saat hari acara berlangsung saja.

Dalam tradisi sinoman dan biyada, ruang-ruang yang ada berubah secara fleksibel sifat teritorialitasnya, bahkan sifat teritorialitas rumah yang ada pada tetangga kanan, kiri, depan, dan atau belakang juga terpengaruh oleh kegiatan ini. Barliana (2010) mengidentifikasikan pelanggaran terhadap teritori salah satunya adalah invansi teritori, yang berarti seseorang secara fisik memasuki teritori orang lain, biasanya dengan masud mengambil kendali atas teritori tersebut dari pemiliknya. Dalam pelaksanaanny, tradisi sinoman dan biyada ini menginvasi teritori tetangga sekitar, namun tetangga sama sekali tidak merasa terganggu karena teritorinya diinvasi, meskipun sampai terjadi perubahan fungsi publik-privat ruang baik secara mikro maupun meso sebagai akibat dari aktivitas ini. Hal inilah yang menjadikan tradisi ini menarik untuk dikaji. Diharapkan dengan penelitian ini kita dapat melihat toleransi ruang yang terjadi di lingkungan sekitar objek kajian, sehingga dapat mengambil pelajaran dan dapat mengaplikasikan toleransi ruang dalam kehidupan bertetangga kita.

Pembentukan teritori pada fleksibilitas ruang dalam tradisi sinoman dan biyada ini terjadi karena adanya kebutuhan, seperti yang dijelaskan dalam Prijotomo dan Pangarsa (2010) bahwa ruang bukan lagi sesuatu yang ada, melainkan sesuatu yang diadakan. Setting ruang mempengaruhi kualitas interaksi orang dan nilai-nilai yang ingin disampaikan. Toleransi dan keguyuban warga Dusun Karang Ampel menjadikan batas-batas teritori bergeser sehingga teritori dapat meluas sampai teritori tetangga-tetangga samping kanan, kiri, depan, dan ataupun belakang.

Fleksibilitas ruang yang terjadi ditandai dengan adanya perubahan karakteristik dan fungsi publikprivat ruang yang ada. Oleh sebab itu, pembentukan teritori dapat diamati dengan melihat perubahan elemen-elemen tersebut. Hermanto (2008) menyebutkan bahwa karakteristik ruang meliputi bentuk ruang, orientasi ruang, ukuran ruang, pembatas ruang (barriers), kondisi ruang, dan komponen ruang.

Pada dasarnya manusia akan tetap mempertahankan teritorinya dengan batas-batas tertentu. Akan tetapi pergeseran teritori yang terjadi dalam tradisi sinoman dan biyada di dusun Karang Ampel dapat menggeser fungsi ruang publik-privat hunian tetangga sekitar. Dengan demikian, masalahnya adalah bagaimana pendekatan teritori pada fleksibilitas ruang yang terjadi dalam tradisi sinoman dan biyada?. Penelitian ini bertujuan untuk mengidentifikasi dan menganalisis teritori pada fleksibilitas ruang yang terjadi dalam tradisi sinoman dan biyada.

\section{METODE PENELITIAN}

Metode yang digunakan dalam penelitian ini adalah metode penelitian deskriptif kualitatif dengan metode pengambilan sampel purpossive sampling. Sampel dipilih dengan berdasarkan 2 kategori, yaitu: (1) hubungan kekerabatan, apakah objek amatan dikelilingi oleh keluarga dengan hubungan kekerabatan yang dekat ataukah hubungan kekerabatan yang jauh; (2) ketersediaan ruang terbuka (pelataran belakang rumah), apakah objek amatan memiliki pelataran belakang ataukah tidak memiliki. Kriteria ini dipilih untuk melihat apakah ada perbedaan dalam perluasan teritori dalam fleksibilitas ruang yang terjadi dalam tradisi sinoman dan biyada. Berdasar- 
kan kategori tersebut, maka dipilih sebagai berikut: (1) Rumah Pak Sai, sebagai rumah yang dikelilingi dengan kerabat dekat dan memiliki pelataran belakang rumah, dan (2) Rumah Pak Jumari, sebagai rumah yang dikelilingi dengan kerabat yang jauh dan tidak memiliki pelataran belakang rumah.

Data diperoleh dengan melalui observasi langsung di lapangan dan wawancara. Observasi di lapangan dilakukan pada bulan Maret 2012, yang bertepatan dengan bulan Jumadil Akhir, dimana pada bulan tersebut merupakan waktu terbanyak dilaksanakannya hajat di dusun ini. Observasi dilakukan dalam 4 hari, yaitu sejak 3 hari sebelum pelaksanaan hajat $(\mathrm{H}-3)$ sampai dengan hari pelaksanaan hajat (hari $\mathrm{H}$ ), dengan mengamati perubahan-perubahan ruang di dalam rumah dan di sekitarnya, dengan mengacu pada karakteristik ruang yang meliputi (1) Bentuk ruang, (2) Ukuran ruang, (3) Pembatas ruang (barriers), dan (4) Komponen ruang, serta ditunjang dengan analisis terhadap perubahan fungsi ruang publik-privat. Sedangkan untuk pengamatan dalam hal invansi terhadap teritori lingkungan sekitar sangat didukung dari keterangan yang diperoleh dari hasil wawancara.

Perubahan fungsi publik-privat akan mempengaruhi perubahan fungsi teritori. Fungsi teritori disebutkan dalam Laurens (2004) untuk memperoleh privasi untuk pemenuhan beberapa kebutuhan psikologis/dasar manusia (kebutuhan akan identitas, stimulus dan keamanan). Berdasarkan tinjauan terhadap fungsi tersebut, maka hasil analisis dapat mengklasifikasikan perubahan teritori dari hari ke hari berdasar klasifikasi teritori oleh Altman (1984), yaitu (1) Primary territory (teritori primer), yaitu tempat yang ditandai dan dimiliki secara eksklusif atau pribadi oleh seseorang dan orang-orang yang akrab di sekitarnya; (2) Secondary territory (teritori sekunder), yaitu tempat yang ditandai dan dimiliki oleh kelompok sosial atau kelompok kerja tertentu; dan (3) Public territory (teritori publik), yaitu tempat yang terbuka untuk untuk publik atau umum.

Analisis dilakukan dengan mengolah hasil pengamatan perubahan karakteristik ruang dari hari ke hari, dan membandingkan hasil dari kedua kategori sampel. Hasilnya dapat diamati apakah terjadi perbedaan atau kesamaan di antara kedua kategori tersebut, sehingga didapatkan pembentukan teritori berdasarkan perubahan karakteristik dan fungsi publik-privat ruang.

\section{HASIL PEMBAHASAN}

Berdasarkan latar belakang yang telah dikemukakan sebelumnya, maka fleksibilitas ruang yang terjadi diamati dari adanya perubahan-perubahan karakteristik ruang yang memiliki keterkaitan dengan aspek teritori, yaitu bentuk ruang, ukuran ruang, pembatas ruang, dan komponen ruang, dengan secara langsung memperkaitkan elemen-elemen yang berhubungan erat. Selain itu, perubahan fungsi publik privat juga sangat mendukung analisis fungsi teritori, teritori primer, sekunder, ataukah publik.

\section{Pembentukan teritori berdasarkan perubahan bentuk, ukuran, pembatas, dan komponen ruang}

Karakter ruang yang meliputi bentuk, ukuran, pembatas, dan komponen ruang sangat berkaitan satu sama lain. Perubahan bentuk akan mempengaruhi ukuran ruang yang ada. Perubahan bentuk ruang juga dapat diamati dengan adanya batas-batas yang membentuk ruang tersebut, baik batas fix element, semi fix element, maupun batas ruang dengan non fix element.

\section{Rumah Pak Sai}

Berikut identifikasi pembentukan teritori berdasar perubahan bentuk, ukuran, pembatas, dan komponen ruang pada rumah Pak Sai.

Perubahan teritori ruang berdasar perubahan bentuk, ukuran, pembatas, dan komponen ruang rumah Pak Sai dapat dilihat pada Gambar 1.

Berdasarkan identifikasi perubahan bentuk, ukuran, pembatas, dan komponen ruang rumah Pak Sai, maka didapatkan hasil sebagai berikut:

a. Bentuk dan ukuran ruang teritori yang semula persegi dengan luas $70.00 \mathrm{~m} 2$ semakin meluas dari hari ke hari ke lingkungan sekitar, sehingga bentuk ruang teritori menjadi tidak beraturan dan sampai pada hari terakhir (hari $\mathrm{H}$ ) mencapai luasan $247.00 \mathrm{~m} 2$. Ruang teritori mengalami perluasan sebesar $\pm 352 \%$ atau $>3$ kali luasan teritori keseharian.

b. Batas teritori juga semakin meluas ke tetangga sekitar dari hari ke hari, yang pada kondisi keseharian lebih berupa batas-batas fisik yaitu pagar dan dinding, mengalami perubahan menjadi beragam bentuk batas, baik berupa fix element, semi-fix element, dan non-fix element. Semakin mendekati hari $\mathrm{H}$, batas-batas teritori semakin dominan dengan batas semi-fix element dan nonfix element, dengan banyaknya penambahanpenambahan komponen ruang yang berupa perabot-perabot di beberapa tempat di lingkungan sekitar, salah satu contoh dengan penempatan loud speaker di jalan. Walaupun bukan merupakan fix element, penempatan loud speaker di jalan ini menandai batas teritori ruang secara jelas. 
Tabel 1. Pembentukan Teritori berdasar Perubahan Bentuk, Ukuran, Pembatas, dan Kompunen Ruang

\begin{tabular}{|c|c|c|}
\hline & Bentuk \& Ukuran & Pembatas \\
\hline $\begin{array}{l}\text { Kondisi } \\
\text { keseharia }\end{array}$ & $\begin{array}{l}\text { Teritori melingkupi area rumah, pelataran } \\
\text { depan, dan belakang rumah, dengan } \\
\text { bentukan denah rumah persegi panjang } \\
\text { dengan ukuran } 5.00 \times 9.00 \mathrm{~m} \text {, sehingga luas } \\
\text { bangunan rumah adalah } 45.00 \mathrm{~m} 2 \text { dengan } \\
\text { luas tanah } 70.00 \mathrm{~m} 2 \text {. }\end{array}$ & $\begin{array}{l}\text { Teritori dibatasi dengan fix element } \\
\text { berupa pagar setinggi } 1 \mathrm{~m} \text { pada } \\
\text { pelataran depan; semi fix element } \\
\text { berupa batas cucuran air hujan dari } \\
\text { atap rumah; dan non fix element } \\
\text { berupa pohon pada pelataran belakang }\end{array}$ \\
\hline $\begin{array}{l}\text { Kondisi } \\
\mathrm{H}-3\end{array}$ & $\begin{array}{l}\text { Teritori meluas ke area tetangga belakang, } \\
\text { yaitu di bagian pelataran belakang tetangga } \\
\text { dan dapur tetangga, sehingga bentuk teritori } \\
\text { sudah tdk beraturan dan meluas sehingga } \\
\text { luasan teritori menjadi } \pm 80.00 \mathrm{~m} 2\end{array}$ & $\begin{array}{l}\text { Penambahan wilayah teritori dibatasi } \\
\text { dengan fix element yang berupa } \\
\text { idinding pemisah ruang dapur teangga, } \\
\text { dan non fix element yang berupa } \\
\text { drum-drum air di pelataran belakang } \\
\text { tetangga }\end{array}$ \\
\hline
\end{tabular}

Komponen

Rumah Pak Sai

Komponen ruang yaitu berupa perabot dan vegetasi pada kondisi eksisting sebagai berikut:

Teras depan: pohon, rumput, dan pagar

g Ruang tamu: set sofa

Ruang tengah: set sofa, tv

Kamar 1\&2: tempat tidur, lemari

Gudang: amben

Dapur: pawonan, meja, genthong air

Pelataran belakang: pohon, amben (bale-

bale), genthong besar

\section{Rumah Pak Sai}

Teras depan: pohon, rumput, pagar, set sofa

, Ruang tamu: karpet, timbunan kelapa utuh

Ruang tengah: set sofa, tv

Kamar 1: tempat tidur, lemari

Kamar 2: sebagai padaringan (tempat sakral)

Gudang: amben (ditumpuk banyak barang)

Dapur: pawonan, pawonan tambahan, meja, genthong air

Pelataran belakang: pohon, amben (bale-

bale), genthong besar, pawonan njenang

Kondisi Bentuk ruang teritori semakin tidak

H-2 beraturan dan meluas hampir ke seluruh ruang di tetangga belakang, gang kanan kiri dan sebagian ruang di tetangga kiri, sehingga luasan teritori menjadi \pm 147.00 $\mathrm{m} 2$
Selain batas-batas yang terbentuk di hari sebelumnya, batas bertambah sehingga batas fix element berupa dinding bata tetangga belakang yang membatas ruang tidur dan seluruh ruang yang terpakai di dalam rumah tersebut, dan non fix element berupa tikar sebagai tempat menjemur daun pisang di tetangga sebelah kanan.

\section{Rumah Pak Sai}

Teras depan: pohon, rumput, pagar, set sofa Ruang tamu: karpet ,tumpukan keropak Ruang tengah: meja disusun 2 tumpuk untuk tempat makanan dan kue

Kamar 1: tempat tidur, lemari

Kamar 2: sebagai padaringan (tempat sakral) Gudang: amben (ditumpuk banyak barang) Dapur: pawonan, pawonan tambahan, meja, genthong air

Pelataran belakang: pohon, genthong besar, pawonan njenang, pawonan tambahan.

Tetangga belakang

Teras belakang: drum-drum air

Dapur: kompor gas, tikar, bahan-bahan yang akan dimasak

Kondisi Ruang teritori semakin meluas ke 2 rumah Batas teritori yang terbentuk di depan Rumah Pak Sai

H-1 tetangga belakang, tetangga samping kanan kiri, dan sebagian jalan raya di depan rumah sehingga bentuk ruang teritori tidak beraturan dan luasan mencapai $+227.00 \mathrm{~m} 2$ rumah dibatasi dengan semi-fix element berupa pemasangan terop, non fix element berupa meja-meja Ruang tengah: meja disusun 2 tumpuk

kue yang diletakkan di gang sebelah Kamar 1: tempat tidur, lemari kanan rumah.

Ruang tamu: karpet
Teras depan: tikar

Kamar 2: sebagai padaringan (tempat sakral) Gudang: amben (ditumpuk banyak barang) Dapur: pawonan, pawonan tambahan, meja, genthong air

Pelataran belakang: pohon, genthong besar, pawonan njenang, pawonan tambahan,

Tetangga belakang, kanan, kiri,

Sebagai tempat menyimpan kompor, tikar untuk ibu-ibu bekerja, drum-drum air, amben, menyimpan sofa-sofa, alat-alat memasa, bahan dan makanan jadii, dan kursi tamu pengunjung 
Lanjutan: Tabel 1

\begin{tabular}{|c|c|c|c|}
\hline & Bentuk \& Ukuran & Pembatas & Komponen \\
\hline $\begin{array}{l}\text { Kondisi } \\
\text { hari } \mathrm{H}\end{array}$ & $\begin{array}{l}\text { Bentuk teritori semakin tidak beraturan dan } \\
\text { meluas sampai ke seberang jalan depan } \\
\text { rumah, kanan kiri rumah, dan luasan } \\
\text { teritori menjadi } \pm 247.00 \mathrm{~m} 2\end{array}$ & $\begin{array}{l}\text { Batas teritori yang trbentuk di depan } \\
\text { rumah selain terop juga adanya non-fix } \\
\text { element berupa loud speaker yang } \\
\text { sangat besar yang terpasang di jalan }\end{array}$ & $\begin{array}{l}\text { Rumah Pak Sai } \\
\text { Komponen ruang hampir sama dengan hai } \\
\text { H-1, perubahan terletak pada teras depan } \\
\text { rumah yg dijadikan tempat makan para tamu, } \\
\text { sehingga terdapat perlengkapan makan di } \\
\text { area ini. } \\
\text { Tetangga belakang, kanan, kiri } \\
\text { Sebagai tempat menyimpan kompor, tikar } \\
\text { untuk ibu-ibu bekerja, drum-drum air, amben, } \\
\text { menyimpan sofa-sofa, alat-alat memasa, } \\
\text { bahan dan makanan jadii, dan kursi tamu } \\
\text { pengunjung } \\
\text { Jalan depan } \\
\text { Pelaminan, kursi dan meja tamu }\end{array}$ \\
\hline
\end{tabular}

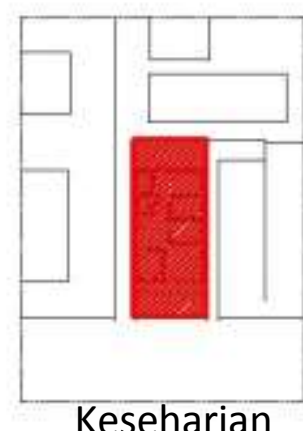

Keseharian

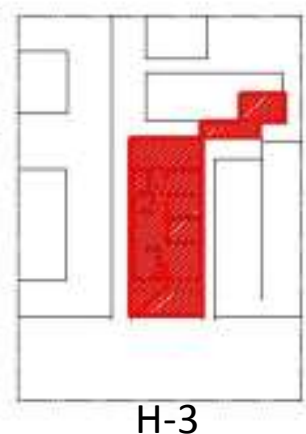

$\mathrm{H}-3$

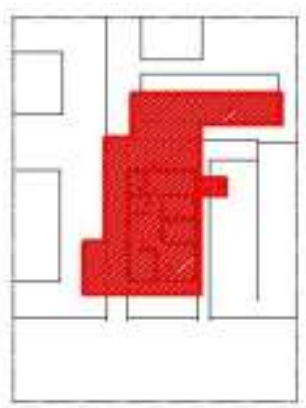

$\mathrm{H}-2$

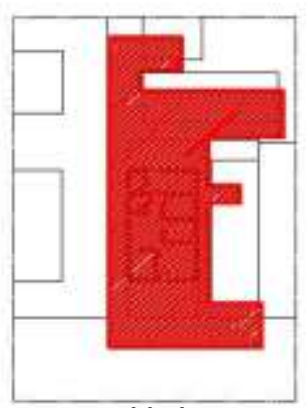

$\mathrm{H}-1$

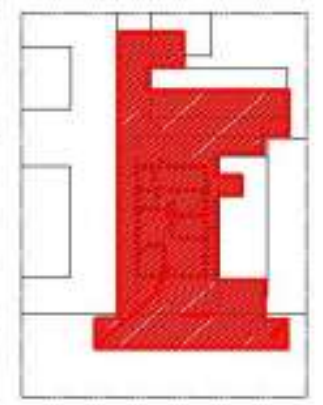

Hari $\mathrm{H}$

Teritori ruang Pak Sai

Gambar 1. Perubahan teritori ruang Pak Sai berdasar perubahan bentuk, ukuran, pembatas, dan komponen ruang

Komponen ruang yang berupa perabot juga mengalami pergeseran dari hari ke hari. Meskipun berupa perabot, namun mampu menjadi penanda perluasan teritori. Komponen ruang sangat berkaitan dengan fungsi ruang, maka dengan adanya perubahan perabot, maka fungsi ruang pun akan turut berubah dan mempengaruhi jenis teritori yang ada di dalamnya, apakah teritori tersebut tetap merupakan teritori primer, sekunder, ataupun berubah menjadi teritori publik. Salah satu contoh pada teritori Pak Sai, yaitu penempatan kompor di ruang tengah tetangga belakang. Pada awalnya ruang tersebut merupakan teritori primer tetangga, dengan adanya perletakan kompor maka terjadi invasi teritori oleh
Pak Sai dan menjadikannya area tersebut teritori publik milik Pak Sai.

\section{Rumah Pak Jumari}

Berikut identifikasi pembentukan teritori berdasar perubahan bentuk, ukuran, pembatas, dan komponen ruang pada rumah Pak Jumari.

Perubahan teritori ruang rumah Pak Jumari berdasar perubahan bentuk, ukuran, pembatas, dan komponen ruang dapat dilihat pada Gambar 2.

Berdasarkan identifikasi perubahan bentuk, ukuran, pembatas, dan komponen ruang rumah Pak Jumari, maka didapatkan hasil sebagai berikut: 
Tabel 2. Pembentukan Teritori berdasar Perubahan Bentuk, Ukuran, Pembatas, dan Kompunen Ruang

\begin{tabular}{|c|c|c|}
\hline & Bentuk \& Ukuran & Pembatas \\
\hline $\begin{array}{l}\text { Kondisi } \\
\text { keseharia }\end{array}$ & $\begin{array}{l}\text { Teritori melingkupi area rumah dan pelataran } \\
\text { depan, dinding belakang berhimpitan dengan } \\
\text { dinding belakang tetangga, sehingga teritori } \\
\text { berbentuk persegi dengan ukuran } \\
6.00 \times 10.00 \mathrm{~m} \text {, dengan tambahan teras depan } \\
\text { ukuran } 2.50 \times 6.00 \mathrm{~m} \text {, sehingga luasan teritori } \\
\text { rumah pak Jumari adalah } 75.00 \mathrm{~m} 2\end{array}$ & $\begin{array}{l}\text { Teritori dibatasi dengan fix element } \\
\text { berupa dinding pagar setinggi } 50 \mathrm{~cm} \\
\text { dan dinding bata yang berdampinga } \\
\text { dengan dinding tetangga kanan dan } \\
\text { belakang. Batas kiri, berbataskan } n o \\
\text { fix element yaitu batas imajiner } \\
\text { cucuran air hujan dari atap rumah }\end{array}$ \\
\hline $\begin{array}{l}\text { Kondisi } \\
\mathrm{H}-3\end{array}$ & $\begin{array}{l}\text { Teritori mulai meluas ke area tetangga kanan } \\
\text { di bagian dapur, sehingga bentuk teritori } \\
\text { mulai tidak beraturan. Luasan teritori adalah } \\
100.00 \mathrm{~m} 2\end{array}$ & $\begin{array}{l}\text { Batas teritori meluas hingga dapur } \\
\text { tetangga yang dibatasi dengan fix } \\
\text { element berupa dinding pemisah } \\
\text { ruang,dan semi-fix element berupa } \\
\text { perabot yang diletakkan di gang } \\
\text { belakang rumah. }\end{array}$ \\
\hline
\end{tabular}

\section{Komponen}

Rumah Pak Jumari

Komponen ruang yaitu berupa perabot dan vegetasi pada kondisi eksisting sebagai berikut: berbentuk persegi dengan ukuran dengan dinding tetangga kanan dan berikut: ukuran $2.50 \times 6.00 \mathrm{~m}$, sehingga luasan teritori fix element yaitu batas imajiner $(50 \mathrm{~cm})$

Ruang tamu: set sofa, lemari Ruang tengah: kursi-kursi, tv Kamar 1\&2: tempat tidur, lemari Dapur: pawonan, meja, genthong, kompor gas

\section{Rumah Pak Jumari}

Teras depan: rumput, dinding pagar rendah (50cm)

Ruang tamu: tikar, lemari, tv

Ruang tengah: meja, tikar

Kamar 1: tempat tidur, lemari

Kamar 2: menjadi sarongan/padaringan

Dapur: pawonan, meja, genthong, kompor gas

Gang belakang: penyimpanan kelapa utuh Tetangga kanan

Dapur: alat-alat mengolah makanan

(baskom, pisau, dingklik)

Kondisi Bentuk teritori semakin tidak beraturan

H-2 karena adanya perluasan teritori ke arah tetangga belakang dan dapur tetangga sebel kiri. Teritori pada $\mathrm{H}-2$ ini mencapai luasan $125.00 \mathrm{~m} 2$
Perluasan teritori dibatas dengang fix Rumah Pak Jumari element yang berupa dinding pemisah Teras depan: sofa hruang dapur dan ruang lainnya di tetangga. Penandaaan perluasan teritori ditandai dengan komponen dan Kamar 1: tempat tidur, lemari kegiatan yang ada dapur tetangga tersebut. Ruang tengah: meja, tikar,
Ruang tamu: tikar, lemari, tv, meja susun 2

\section{Kamar 2: menjadi sarongan/padaringan} Dapur: pawonan, meja, genthong, kompor gas

Tetangga kanan dan kiri

Dapur: alat-alat mengolah makanan (baskom, pisau, dingklik)

Tetangga belakang

Dapur: kompor gas dan alat mengolah makanan

Kondisi Teritori pada H-1 semakin meluas ke arah H-1 depan rumah hingga menutup jalan raya depan rumah. Bentuk teritori tidak beraturan dan luasan mencapai $170.00 \mathrm{~m} 2$
Batas teritoripada perluasan teritori di Rumah Pak Jumari depan rumah ditandai dengan semi-fix Teras depan: kursi dan meja tamu, element berupa pemasangan terop, kursi, dan meja untuk para tamu di pelataran depan dan jalan raya, serta pemasangan loud-speaker di pinggir jalan.

pelaminan Ruang tengah: meja, tikar,

Kamar 1: tempat tidur, lemari
Ruang tamu: tikar, lemari, tv, meja susun 2

Kamar 2: menjadi sarongan/padaringan

Dapur: pawonan, meja, genthong, kompor gas

Gang kiri: meja-meja makanan Tetangga kanan dan kiri

Dapur: alat-alat mengolah makanan (baskom, pisau, dingklik)

Tetangga belakang

Dapur: kompor gas dan alat mengolah makanan 
1. Bentuk dan ukuran ruang teritori yang pada kesehariannya berbentuk persegi dengan luasan $75.00 \mathrm{~m} 2$ mengalami perluasan dari hari ke hari pada saat tradisi sinoman dan biyada, hingga pada hari $\mathrm{H}$ luasan ruang teritori sebesar $230.00 \mathrm{~m} 2$ dengan bentuk yang tidak beraturan. Dalam prosentase, perluasan teritori ini mencapai 306\% atau > 3 kali luas teritori pada keseharian.

2. Batas teritori pada perluasan teritori rumah Pak Jumari dari hari ke hari didominasi oleh fix element berupa dinding pembatas ruang di dalam rumah tetangga. Hal ini disebabkan karena posisi rumah Pak Jumari yang tidak emiliki teras belakang, dan samping kanan dan belakang dinding rumah berbatasan langsung dengan dinding tetangga. Batas berupa semi-six element lebih banyak terdapat pada area depan rumah Pak Jumari, dengan adanya pemasangan terop dan peletakan komponen-komponen ruang pada area ini.

3. Komponen ruang dalam rumah Pak Jumari tidak terlalu signifikan perubahan dari hari ke hari. Hal ini terjadi karena posisi rumah Pak Jumari yang berhimpitan dengan tetangga dan tidak memiliki

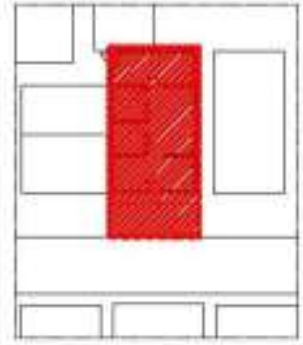

Keseharian

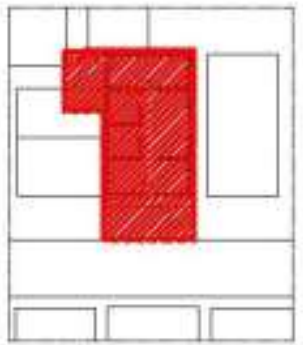

$\mathrm{H}-3$

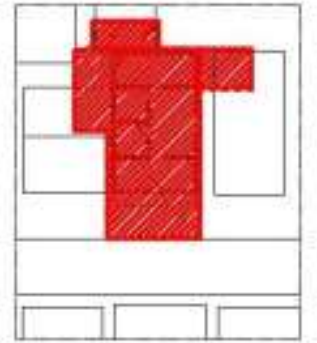

$\mathrm{H}-2$

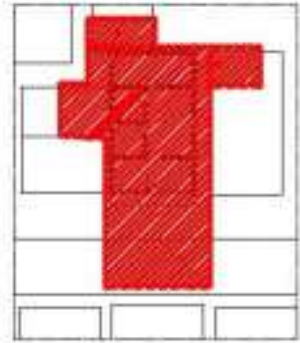

$\mathrm{H}-1$

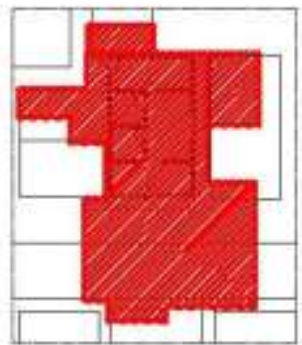

Hari $\mathrm{H}$

Teritori ruang Pak Sai

Gambar 2. Perubahan teritori ruang Pak Jumari berdasar perubahan bentuk, ukuran, pembatas, dan komponen ruang

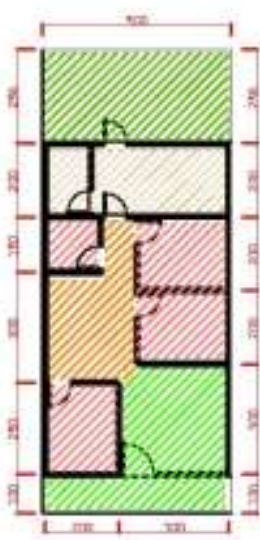

Keseharian

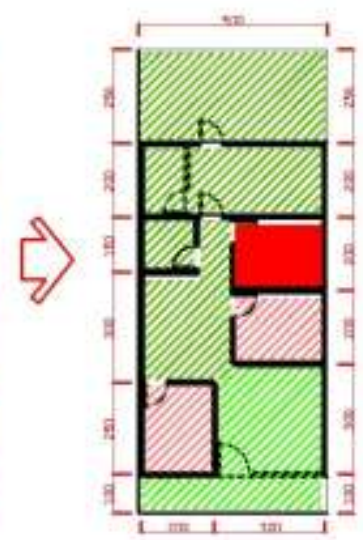

$\mathrm{H}-3 \mathrm{~s} / \mathrm{d} \mathrm{H}-1$

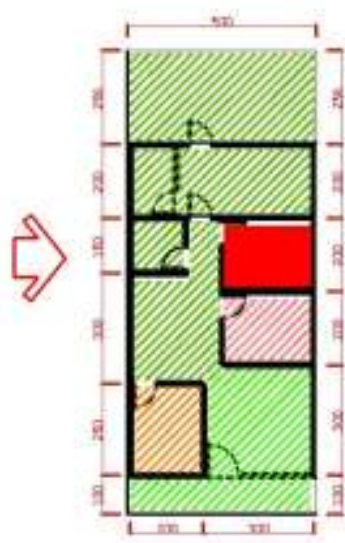

Hari H

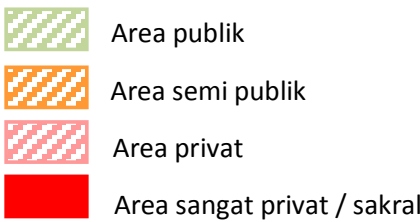

Area sangat privat / sakral
Fungsi publik privat pada kondisi keseharian

sebagai berikut:

- Publik (26.50m2): rg. Tamu, teras depan, teras belakang

- Semi publik(18.50m2): rg. Tengah

- Privat (17m2): kamar tidur, dapur
Fungsi publik privat pada $\mathrm{H}-3$ Fungsi publik privat pada hari $\mathrm{H}$ s/d H-1 sebagai berikut:

- Publik (47m2): rg. Tamu, teras depan, teras belakang, rg. Tengah, kamar belakang, dapur, kamar mandi,

- Privat $(10 \mathrm{~m} 2)$ : kamar tidur

- Sangat privat/sakral (5m2): kamar tidur yang dijadikan sarongan/padaringan sebagai berikut:

- Publik (47m2): rg. Tamu, teras depan, teras belakang, $\mathrm{rg}$. Tengah, kamar belakang, dapur, kamar mandi,

- Semi publik (5m2): kamar tidur untuk rias pengantin

- Privat $(5 \mathrm{~m} 2)$ : kamar tidur

- Sangat privat/sakral (5m2): kamar tidur yang dijadikan sarongan/padaringan

Gambar 3. Perubahan teritori ruang Pak Sai berdasar perubahan fungsi publik-privat skala mikro 
teras belakang, sehingga pergerakan perpindahan komponen ruang diminimalisir dengan mempersiapkan perletakan komponen-komponen ruang tersebut sejak H-3. Oleh sebab itu fungsi dan jenis teritori yang berada di dalam rumah pun tidak banyak mengalami perubahan jenis teritori, apakah teritori primer, sekunder, ataupun publik. Penanda perluasan teritori berdasarkan komponen ruang lebih terjadi di area luar rumah, yaitu di tetangga kanan, kiri, belakang, dan depan.

\section{Pembentukan teritori berdasarkan fungsi publik dan privat}

\section{Rumah Pak Sai}

Rumah merupakan teritori primer jika ditinjau dari skala meso ataupun makro, akan tetapi jika ditinjau skala mikro, maka di dalamnya akan terdapat jenis teritori-teritori primer,sekunder, dan publik. Hal ini sangat berkaitan erat dengan fungsi publik privat di dalamnya. Perubahan teritori di dalam rumah berdasar perubahan fungsi publik dan privat yang terjadi di dalam rumah Pak Sai dapat dilihat pada Gambar 3.

Perubahan fungsi publik-privat yang terjadi di dalam rumah Pak Sai berkaitan erat dengan adanya perubahan komponen ruang di dalamnya yang mengakibatkan aktivitas yang terjadi di dalamnya berubah pula. Dapat dilihat bahwa dalam tradisi sinoman dan biyada ini, ruang-ruang semakin terbuka, dan dari hari ke hari semakin didominasi area publik. Teritori primer terbentuk dari area sakral dan privat, yaitu yang berupa padaringan/sarongan dan kamar tidur. Teritori sekunder terbentuk dari area semi publik yang pada tradisi ini hanya terdapat pada saat hari $\mathrm{H}$, yaitu di kamar tidur, karena menjadi kamar untuk rias pengantin, sehingga beberapa orang umum boleh masuk di dalamnya. Teritori publik terbentuk dari area publik, yaitu ruang tamu, teras depan, teras belakang, ruang tengah, kamar belakang, dapur, dan kamar mandi. Perubahan jenis teritori terletak pada ruang tengah dan dapur, yang semula adalah teritori sekunder, pada saat tradisi sinoman dan biyada ruang ini menjadi teritori publik.

Secara meso, perubahan teritori berdasar perubahan fungsi ruang publik privat pada lingkungan sekitar rumah Pak Sai dapat dilihat pada Gambar 4.

Dalam skala meso, terlihat invasi teritori Pak Sai terhadap lingkungan sekitar, baik tetangga kanan, kiri, depan, dan belakang. Dalam skala meso, teritori tetangga adalah teritori primer, dan teritori publik adalah teritori Pak Sai. Dapat dilihat bahwa dari hari ke hari teritori publik semakin meluas menginvasi teritori primer tetangga. Dapat dilihat bahwa invasi teritori yang terjadi di rumah tetangga hanya menginvasi area publik dan semi publik, yaitu ruang tamu, ruang tengah, dan dapur. Area privat tetangga berupa kamar tidak terinvasi oleh perluasan teritori, sehingga tetangga masih memiliki privasi dan ruang gerak di dalam teritorinya sendiri, walaupun tidak terlalu luas.

\section{Rumah Pak Jumari}

Perubahan teritori berdasar perubahan fungsi publik dan privat yang terjadi di dalam rumah Pak Jumari dapat dilihat pada Gambar 5.

Sebagaimana yang telah diungkapkan sebelumnya, bahwa fungsi publik privat bekaitan erat dengan peletakan komponen ruang di dalamnya. Posisi rumah yang berhimpitan dengan tetangga sebelah atau belakang menyebabkan perubahan komponen diminimalisir oleh penyelenggara hajat dengan menempatkan komponen yang tidak berubah di ruang

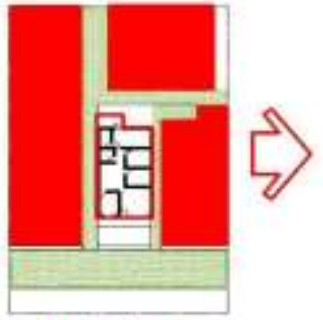

Eksisting

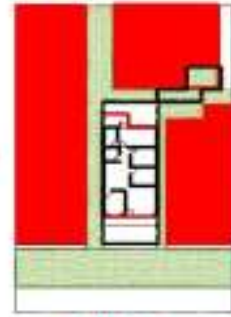

$\mathrm{H}-3$

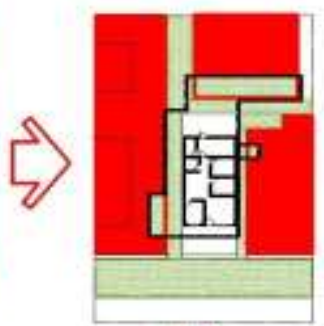

$\mathrm{H}-2$

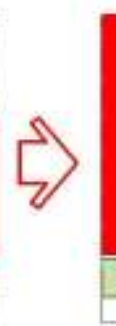

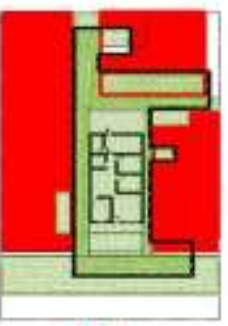

$\mathrm{H}-1$

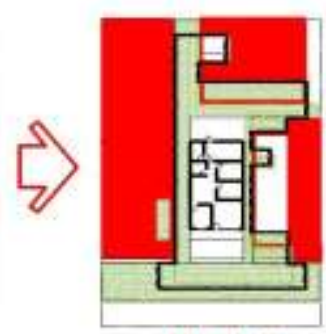

Hari H
Area publik

Area privat (tetangga)

Gambar 4. Perubahan teritori ruang Pak Sai berdasar perubahan fungsi publik-privat skala meso 


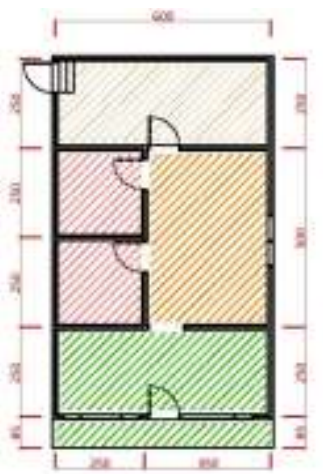

Keseharian

Fungsi publik privat pada kondisi keseharian sebagai berikut:

- Publik (20.00m2): rg. Tamu, teras depan

- Semi publik (32.50m2): rg. Tengah

- Privat (12.50m2): kamar tidur, dapur
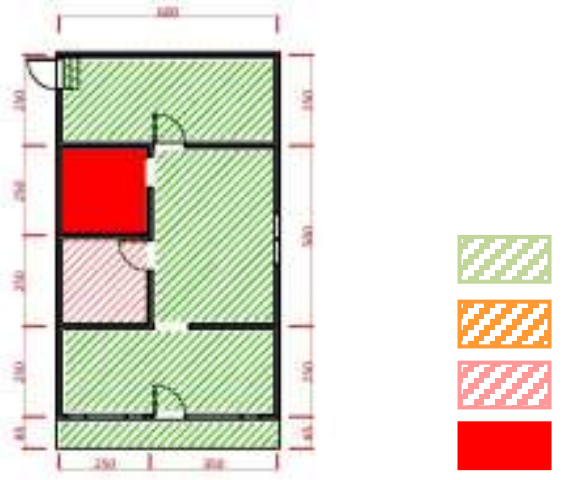

Area publik

Area semi publik

Area privat

Area sangat privat / sakral

\section{$\mathrm{H}-3 \mathrm{~s} / \mathrm{d} \mathrm{H}-1$}

Fungsi publik privat pada $\mathrm{H}-3 \mathrm{~s} / \mathrm{d}$ hari $\mathrm{H}$ sebagai berikut:

- Publik (52.50m2): rg. Tamu, teras depan, rg.

Tengah, dapur, kamar mandi,

- Privat $(6.25 \mathrm{~m} 2)$ : kamar tidur

- Sangat privat/sakral (6.25m2): kamar tidur yang dijadikan sarongan/ padaringan

Gambar 5. Perubahan teritori ruang Pak Jumari berdasar perubahan fungsi publik-privat skala mikro

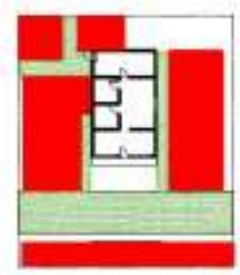

Eksisting

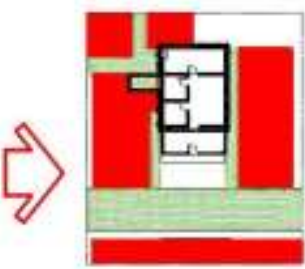

$\mathrm{H}-3$

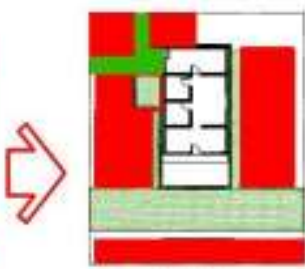

$\mathrm{H}-2$

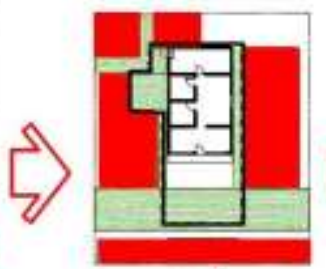

$\mathrm{H}-1$

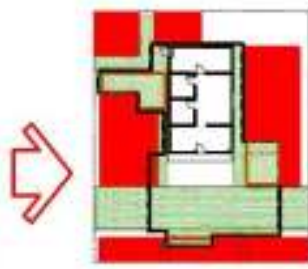

Hari H

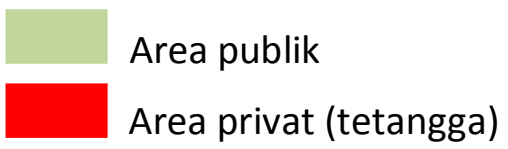

Gambar 6. Perubahan teritori ruang Pak Sai berdasar perubahan fungsi publik-privat skala meso

dalam. Perubahan terjadi dimulai dari $\mathrm{H}-3$ yaitu perubahan dari area semi publik, yaitu ruang tengah dan dapur, menjadi area publik; area privat (kamar tidur) berubah menjadi area sakral, yaitu menjadi sarongan/padaringan. Sama halnya dengan teritori yang terbentuk di rumah Pak Sai, teritori primer terbentuk dari area sakral dan privat, yaitu sarongan/ padaringan dan kamar tidur; dan teritori publik terbentuk dari area publik, yaitu teras depan, ruang tamu, ruang tengah, dan dapur. Pada rumah Pak Jumari ini tidak tedapat teritori sekunder, karena tidak ada area semi publik di dalamnya. Hal ini dikarenakan acara yang diselenggarakan Pak Jumari adalah ngunduh mantu, sehingga tidak disediakan kamar untuk merias pengantin, yang merupakan area semi publik.
Secara meso, perubahan teritori berdasar perubahan fungsi ruang publik privat pada lingkungan sekitar rumah Pak Jumari dapat dilihat pada Gambar 6.

Dalam skala meso, perubahan teritori berdasar perubahan fungsi publik privat pada rumah Pak Jumari tidak berbeda dengan rumah Pak Sai. Teritori primer, yaitu rumah tetangga, dari hari ke hari semakin menyempit dan menjadi teritori publik milik Pak Jumari. Perluasan teritori di dalam teritori primer tetangga tidak sampai ke area privat tetangga, hanya pada area publik dan semi pulik saja, yaitu pada teras, ruang tamu, ruang tengah, dan dapur. 
Hasil analisis terhadap perbandingan pembentukan teritori Rumah Pak Sai dan Pak Jumari

1. Kriteria hubungan kekerabatan dengan tetangga sekitar dan ketersediaan area terbuka pada objek amatan ternyata tidak berpengaruh terhadap invasi teritori ke tetangga sekitar, hal ini dapat dilihat bahwa bentuk perluasan teritori antara rumah Pak Sai dengan Pak Jumari memiliki kesamaan yaitu bentuk tidak beraturan, dan perluasan teritori sama-sama sebesar 3 kali teritori keseharian. Hal ini mengungkapkan bahwa walaupun tetangga sekitar bukan kerabat dekat, tetangga dengan sukarela membiarkan teritorinya diinvasi oleh tetangga yang menyelenggarakan hajat, sejalan dengan prinsipnya bahwa masyarakat Dusun Karang Ampel siap membantu tetangga dan keluarga khususnya dalam 3 hal, yaitu kematian (kesripahan), punya hajat (sinoman dan biyada), dan membangun rumah (sayan).

2. Pembentukan teritori berdasar batas ruang lebih berkaitan dengan posisi rumah terhadap lingkungan sekitar, yaitu apakah rumah tersebut memiliki teras belakang, dan apakah dindingnya berhimpitan dengan dinding tetangga (tidak ada gang di antara rumah-rumah). Hal ini menyebabkan batas teritori rumah yang berhimpitan dengan dinding tetangga (rumah Pak Jumari) lebih didominasi dengan batas fix-element berupa dinding yang berbatasan dengan ruang sebelah. Untuk rumah yang memiliki teras dan gang (rumah Pak Sai) lebih banyak ditemukan pembatas-pembatas berupa semi-fix element dan non-fix element karena masih terdapat banyak ruang terbuka di sekitarnya.

3. Perubahan komponen ruang yang berkaitan erat dengan fungsi teritori primer, sekunder, ataupun publik lebih banyak terpengaruh faktor lokasi rumah terhadap lingkungan sekitar. Faktor kekerabatan tidak memiliki pengaruh di dalam perubahan komponen ruang. Perubahan komponen ruang untuk rumah yang memiliki ruang terbuka (rumah Pak Sai) lebih banyak mengalami perubahan di dalam dan di luar ruang, sedangkan untuk untuk rumah Pak Jumari perubahan komponen ruang lebih banyak terjadi di luar rumah Pak Juamri, yaitu di tetangga sekitar, teras, dan jalan depan. Hal ini dikarenakan pergerakan perpindahan komponen ruang diminimalisir dengan mempersiapkan perletakan komponen-komponen ruang tersebut sejak $\mathrm{H}-3$.

4. Pada skala mikro, pembentukan teritori berdasarkan perubahan fungsi publik privat antara rumah
Pak Sai dengan rumah Pak Jumari tidak terlalu berbeda. Teritori publik dari hari ke hari semakin meluas dan teritori primer semakin menyempit. Teritori primer terbentuk dari area sakral dan privat, yang terdapat pada sarongan/padaringan dan kamar tidur. Teritori publik terbentuk dari area publik, yaitu teras depan, ruang tamu, ruang tengah, dapur, teras belakang. Teritori sekunder yang terbentuk pada rumah Pak Sai dan tidak ada di rumah Pak Jumari bukan disebabkan oleh kriteria kekerabatan ataupun lokasi rumah, namun karena jenis hajatan yang berbeda.

5. Pada skala meso, pembentukan teritori berdasar perubahan fungsi publik privat antara teritori rumah Pak Sai dan Pak Jumari tidak berbeda pula. Dari hari ke hari teritori publik semakin meluas ke lingkungan sekitar, baik tetangga samping kanan, kiri, depan, dan belakang, dan teritori primer (rumah tetangga) semakin menyempit. Akan tetapi walaupun menyempit, invasi teritori hanya terjadi pada area publik dan semi publik tetangga, yaitu pada teras, ruang tamu, ruang tengah, dan dapur, sedangkan untuk area privat berupa kamar tidak turut terinvasi.

\section{KESIMPULAN}

Berdasarkan hasil identifikasi dan analisis terhadap teritori pada fleksibilitas ruang dalam tradisi sinoman dan biyada di Dusun Karang Ampel, maka didapatkan hasil bahwa hubungan kedekatan kekerabatan tidak berpengaruh terhadap pembentukan perluasan teritori, akan tetapi perbedaan pola pembentukan teritori lebih karena dipengaruhi faktor ketersediaan ruang terbuka (pelataran belakang).

Teritori yang terbentuk dengan latar belakang hubungan kekerabatan dekat sama hasilnya dengan yang berlatar belakang hubungan kekerabatan jauh. Perluasan teritori terhadap tetangga sampai kepada area publik dan semi publik, yaitu teras, ruang tamu, ruang tengah, dan dapur. Faktor ketersediaan ruang terbuka (pelataran belakang) menjadikan batas teritori yang sedikit berbeda. Objek amatan yang memiliki ruang terbuka teritorinya lebih banyak terbentuk dengan batas-batas semi-fix element dan non fix element, akan tetapi yang tidak ada ruang terbukanya lebih didominasi dengan batas fix element berupa dinding-dinding pembatas ruang. Selain itu perubahan fungsi publik privat ruang pada objek amatan yang memiliki pelataran belakang lebih fleksibel jika dibandingkan dengan objek yang tidak memiliki pelataran belakang. 


\section{Arti kata-kata Jawa}

Pawonan: Dasar untuk tungku memasak dengan menggunakan bahan bakar kayu

Njenang : Proses memasak jenang (dodol)

Sarongan/padaringan: Ruang untuk menyimpan bahan-bahan yang digunakan unuk hajat yang tidak boleh dimasuki siapapun kecuali yang sedang punya hajat

Genthong: Guci gerabah besar tempat menyimpan air

Amben : Tempat istirahat semacam bale-bale

Dingklik : Kursi pendek

\section{DAFTAR PUSTAKA}

Altman, I. \& M. Chemers (1984). Culture and Environment, Press Syndicate of the University of Cambridge, Cambridge.
Assulaiman, A.K.A. bin J. (2009). dalam http:// pejuangperadaban.blogspot.com. Diunduh pada tanggal 15 Oktober 2010.

Barliana, S. (2010). Arsitektur, Komunitas, dan Modal Sosial, Metatekstur Penerbit Diskursus, Bandung.

Hermanto, H. (2008). Tesis, Faktor faktor Yang Berpengaruh Terhadap Perubahan Fungsi Ruang di Serambi Pasar Induk Wonosobo, Universitas Diponegoro, Semarang.

Laurens, J.M. (2004). Arsitektur dan Perilaku Manusia, Penerbit PT. Grasindo, Jakarta.

Prijotomo, J. dan G.W. Pangarsa (2010). dalam http://ruangarsitektur.com. Diunduh pada tanggal 5 Januari 2012.

Ronald, A. (2005). Nilai-nilai Arsitektur Rumah Tradisional Jawa, Gadjah Mada University Press, Yogyakarta. 